\title{
EL CONSTITUCIONALISMO SOCIAL WEIMARIANO EN EL PENSAMIENTO FRANCÉS DE ENTRE-GUERRAS ${ }^{1}$ \\ WEIMAR SOCIAL CONSTITUTIONALISM IN FRENCH LEGAL THINKING IN THE INTERWAR PERIOD
}

\author{
Carlos Miguel Herrera \\ Université de Cergy-Pontoise, CPJP
}

\begin{abstract}
Resumen: Este estudio analiza la recepción de la Constitución de Weimar en el pensamiento jurídico durante el período de entreguerras, a través un ángulo específico: la incorporación de normas sociales en el ordenamiento constitucional. Aunque los primeros comentaristas identificaron rápidamente las innovaciones que contenía, su trascendencia se vio minimizada o relacionada únicamente con el problema de la representación. La perspectiva cambia a finales de los años 1920 y 1930, sobre todo por obra de pensadores marginales en las facultades de derecho. Pero la reacción ante la interpretación de mayor calado por parte del principal teórico alemán del derecho social muestra no sólo los límites de la recepción, sino las dificultades para plasmar un constitucionalismo social.
\end{abstract}

Abstract: This article analyzes the reception of the Weimar Constitution in French legal thinking in the interwar period, from a specific point: the incorporation of social norms at the constitutional order. Although the early commentators quickly identified the innovations, there significance was in general minimized. The perspective changes at the end of the 1920s and 1930s, mainly due to the work of marginal thinkers in law schools. Nevertheless, the reaction against the more rich French interpretation by the main German theorist in Social Law shows not only the limits of reception, but the difficulties for conceiving a social constitutionalism.

Palabras clave: Constitución de Weimar, derecho social, pensamiento jurídico francés, Gurvitch, Sinzheimer

Key Words: Weimar Constitution, Social Law, French Legal Thought, Gurvitch, Sinzheimer

La cuestión del " constitucionalismo social " ilustra bien el problema de la recepción de las ideas weimarianas en Francia, más allá de la especificidad del objeto $^{2}$. La recepción no fue determinante en el desarrollo del ordenamiento francés; en cualquier caso, su presencia fue mucho menos directa que en las

\footnotetext{
${ }^{1}$ Traducción española de la Doctora Patricia Ledesma Fernández (Universidad Complutense de Madrid).

${ }^{2}$ Para un análisis de conjunto de esta recepción, ver Carlos M. Herrera, "¿Adiós a las armas? La recepción de la Constitución de Weimar en el pensamiento jurídico francés de entreguerras", (2011), trad. española en José Luis Villacañas, Jordi Maiso (eds.), Laboratorio Weimar, Tecnos, Madrid, 2019 (en prensa).
} 
constituciones de otros países europeos, como la española de 1931 o aun en la italiana de 1948.

Sin embargo, da cuenta del tipo de dificultad al que se enfrentaba el proyecto de Weimar en la margen izquierda del Rin. Y más allá de las fronteras geográficas, deja entrever un interés teórico detrás de la interrogación propiamente histórica y comparativa, que toca a la naturaleza compleja del constitucionalismo social, su desarrollo a lo largo del siglo XX en una constante tensión entre el (intervencionismo del) Estado y los derechos (sociales).

Volvamos nuestra atención unos instantes a ese momento crucial en la historia constitucional francesa que representa, en 1946, la Constitución de la Cuarta República, o más exactamente, los primeros comentarios que despierta este texto de tan dificil alumbramiento. No había duda, afirmaba por entonces Jean Rivero, de que se trataba de una constitución social, porque ofrecía al Estado un amplio poder de intervención, no limitado por principios absolutos. Además, agregaba Georges Vedel, era la más osada de su clase, porque combinaba estándares programáticos y un gran poder parlamentario para modificar las instituciones existentes ${ }^{3}$. En ambos postulados, la evocación de Weimar estaba prácticamente ausente, perdida entre otras referencias ${ }^{4}$. Ciertamente, nada comparable con lo que ocurre en el proceso constituyente que se estaba desarrollando en Italia, donde la importancia de la Constitución alemana de 1919 estaba muy presente, incluso para indicar sus limites (que debían ser superados). No por nada, el ensayo de Costantino Mortati, editado en 1946 en ese contexto, era uno de los primeros textos en dar a la Constitución weimariana de 1919 un lugar preeminente en el linaje constitucional europeo.

Con este breve recuerdo, ya nos hemos adentrado en el corazón de la especificidad de la recepción francesa de entre-guerras, no solo de la Constitución de Weimar, sino del constitucionalismo social, donde la cuestión de los derechos sociales será absorbida por el intervencionismo estatal.

La Constitución de 1919 fue la primera constitución europea del siglo XX que dio reconocimiento a los derechos sociales, en las secciones sobre "La vida social" y, sobre todo, sobre "La vida económica". Eran constitucionalizados allí -si bien con una técnica jurídica todavía incipiente- el derecho al trabajo, el derecho

\footnotetext{
${ }^{3}$ Ver los ensayos reunidos por ambos autores, en el volumen Les problèmes économiques et la Constitution du 27 octobre 1946, Collection Droit Social, XXXI, 1947. La obra sirvió durante mucho tiempo como marco teórico para el constitucionalismo social francés. Si la doctrina discutía el valor del Preámbulo de 1946 y sus derechos-deuda ("droits-créances"), era principalmente en los poderes del Estado en materia económica, no necesariamente constitucionalizados, que residía la clave para una transformación del sistema legal. Después de todo, estos juristas veían en el Preámbulo demasiadas contradicciones y hasta una gramática pasada de moda. Y no era el Consejo Económico y Social el que les preocupaba ...

${ }^{4}$ No se debía al eventual desprestigio por su supuesta incapacidad para impedir la instalación de un régimen totalitario por vía legal: más bien aparecía en trance a ser superada. En todo caso, la Constitución de 1919 ya no aparecía como tan innovadora en material social, el texto que concitaba quizás mayor atención de parte de los comentaristas era ahora la Constitución soviética de 1936, que guardaba por entonces cierto atractivo, incluso para algunos sectores de la socialdemocracia europea.
} 
a la vivienda, el derecho a la salud, el derecho a la educación, el derecho a la seguridad social, el derecho a la subsistencia, y un grupo de derechos de los trabajadores, ante todo algunas garantías específicas referidas a la asociación sindical.

En verdad estos derechos formaban parte de un conjunto normativo que plasmaba lo que hemos llamado en otro lugar "el dispositivo del constitucionalismo social", formado por tres elementos que se articulan entre sí de manera especifica: la promoción de un principio material de justicia o igualdad en la esfera económica y social -que en el caso de Weimar, se encuentra en el art. 151 que afirma que "la organización de la vida económica debe corresponder a los principios de la justicia y proponerse como objetivo el garantizar a todos una existencia digna del hombre», la limitación de la propiedad privada por su función social, que puede llegar hasta la expropiación o socialización, y la enunciación de los derechos de los trabajadores que también puede incluir, como en el caso del art. 165 de la Constitución alemana, organismos específicos de producción normativa confiados a los actores sociales- ${ }^{5}$.

El constitucionalismo social, con su dispositivo, se ubicó en una perspectiva de transformación de la sociedad por vias institucionales $y$, sobre todo, democráticas, lo que implicó por entonces una ruptura con las viejas visiones de la politica social, de tipo integracionista, que rechazaban la introducción de la cuestión social en el ámbito constitucional, con el fin de mantenerlo limitado al espacio de la administración pública.

Por cierto, la Constitución alemana de 1919 no era, al contrario de lo que se ha sostenido a menudo, la primera expresión de este constitucionalismo social. Ya la Constitución Política de los Estados Unidos Mexicanos de 1917, adoptada en Querétaro, se le había anticipado dos años y, según Boris MirkineGuetzévitch, "en sus tendencias sociales supera a las declaraciones europeas".

Sin entrar a discutir aquí la exactitud de esta afirmación, debe tenerse en cuenta que la Constitución alemana presentaba con todo varias características originales. Por un lado, amplió el alcance de los derechos que comenzaban a designarse como "derechos sociales" (la expresión se encuentra positivada en el artículo 162), y que ya no se limitaban a los "derechos de los trabajadores" que habian sido desarrollados en la Constitución mexicana de $1917^{6}$. En efecto, el constituyente alemán había reconocido una serie de derechos a otros sujetos colectivos, como la familia, los jóvenes o los funcionarios públicos.

Pero incluso dentro de los "derechos de los trabajadores", el texto de Weimar innovó de manera decisiva, otorgando un papel normativo a los sindicatos y organizaciones sociales, obreras y patronales, en materia de regulación económica y reglamentación laboral. Este es el famoso artículo 165, que establecía en su primer párrafo que "los trabajadores y empleados son llamados a

\footnotetext{
${ }^{5}$ Era este dispositivo el que daba su significado específico al constitucionalismo social como concepción o proyecto, involucrando diferencias con los desarrollos constitucionales posteriores a 1945. Ver Carlos M. Herrera, "La teoría constitucional de lo social" (2008), trad. española en Diego Valadés, José Gamas Torruco, François Julien-Laferrière, Eric Millard (eds.), Ideas e instituciones constitucionales en el siglo XX, México, Siglo XXI, 2011, p. 254-274., Carlos M. Herrera, "Estado, constitución y derechos sociales" (2003), trad. española en Carlos M. Herrera, Los derechos sociales, entre Estado y doctrina jurídica, Universidad Externado de Colombia, Bogotá, 2008.

${ }^{6}$ Ver Carlos M. Herrera, "Sobre la significación histórica de la Constitución mexicana de 1917", Anuario de derecho constitucional comparado, VIII, 2018, p. 205-224.
} 
cooperar en pie de igualdad y en común con los empresarios en la reglamentación de los salarios y las condiciones de trabajo, así como en el desarrollo de las fuerzas productivas». Los Consejos Económicos, que se organizaban en tres niveles, el último en el ámbito del Reich, reunían a los representantes de los trabajadores y de los empleadores, con poder consultivo sobre la legislación social y las leyes de socialización, ciertas facultades propias, en un procedimiento enmarcado, e incluso de la iniciativa legislativa.

El mismo artículo, en su segundo párrafo, reconocía la formación de consejos de obreros de fábricas (Betriebsräte) "para salvaguardar sus intereses sociales y económicos»"

Este lugar de las organizaciones obreras en el dispositivo económico, especialmente ante una eventual politica de socialización, era todavia más significativo que otro derecho de los trabajadores, el "derecho a huelga", consagrado en la Constitución mexicana, pero que no estaba garantizado en el texto alemán. Su reconocimiento había sido reclamado en la Asamblea Constituyente, en particular por el partido socialista independiente (USPD), pero los sindicatos socialdemócratas se conformaron con la amplia constitucionalización de la "libertad sindical», confiando en que la democracia haría el resto, ya que la clase obrera era la más numerosa de la población...

No era pues un azar que en Francia el dispositivo social sea puesto en relieve de inmediato en los primeros análisis de la República de Weimar, incluso por los comentarios no jurídicos. Así, Paul Gentizon -corresponsal del Temps en Alemania, quien reuniria sus impresiones y crónicas en dos obras notablesseñaló en la ambición de proclamar "los derechos económicos del individuo", una suerte de eco de 1789. Pero estos principios, decía, no podian ser entendidos sin la "socialización", la principal reivindicación social de las masas. Era el reconocimiento legal de los Consejos de obreros que le parecía la innovación constitucional más audaz, aun juzgando ese cambio como más bien instrumental, oportunista ${ }^{8}$.

A fortiori, cuando aparece un primer libro jurídico sobre la Constitución alemana, en 1921, la cuestión ocupa un lugar central. Su autor, René Brunet estimaba que "la Constitución económica innova mucho más que la Constitución politica", sobre todo por la institución de los Consejos que representaba, según él, "la única idea verdaderamente nueva que ha aparecido en el derecho público de los Estados modernos desde la guerra". Aunque su aplicación e incluso la extensión de la noción le parecían limitadas e imprecisas, también subrayaba el vínculo con una política económica contraria al liberalismo y, en particular, con la nacionalización. Quedaba por ver si este dispositivo era el resultado de una

\footnotetext{
${ }^{7}$ La ley del 4 de febrero de 1920, que los organiza, establece su carácter obligatorio para cualquier empresa, pública o privada, que emplee al menos a 20 personas. Sus atribuciones se referian principalmente a las condiciones de trabajo y los conflictos, y la colaboración en la gestión de la empresa. Los convenios colectivos de trabajo siguen siendo responsabilidad de los sindicatos, que en última instancia también se hacen cargo de la organización de los consejos. Las tensiones reaparecerán más tarde con los comunistas.

${ }^{8}$ Da la impresión, escribirá, de que el intento se ha hecho más bien para frenar el bolchevismo de las clases trabajadoras mediante algunas concesiones antes que para realizar un nuevo derecho o para hacer una transformación. Paul Gentizon, L'Allemagne en République, Payot, París, 1920, p. 201.
} 
turbulencia transitoria o la llegada de un elemento permanente en los Estados modernos ${ }^{9}$.

Si Brunet examinó la cuestión en términos más bien descriptivos, JosephBarthélemy, la figura en ascenso del derecho constitucional francés en ese momento, hacía explícito su juicio en el prefacio a dicha obra. Por lo pronto, entendía que los principios de la nueva Constitución en materia económica expresaban un "carácter socialista o socializante». En efecto, "la nueva Alemania, nacida de un impulso bolchevique y habiéndose confirmado en un movimiento socialdemócrata, necesitaba dar a estas tendencias las satisfacciones compatibles con las necesidades de su recuperación, o incluso, la simple supervivencia de Alemania". No se trataba solamente de una "constitución económica" que se estaba poniendo en marcha, sino también, una visión jurídica dominada por los socialistas $^{10}$.

Los espíritus mejor predispuestos hacia Alemania, como Edmond Vermeil, vincularon esta parte social de la Constitución -siempre considerada como la más innovadora- con el "genio germánico", que dejaría su huella organicista en nociones como Gruppenmensch o Volksstaat. Empero, las ideas de organización e integración podrían obstaculizar "la acción de las fuerzas democráticas libres". Asegurando que es "la primera y única constitución" en reconocer tales normas, Vermeil consideraba que el sistema impone al Estado, para satisfacer a los socialistas moderados, un "sovietismo atenuado". Sería una nueva forma para "esta incesante critica que los alemanes hacen de la democracia occidental o formal". Aún así, "su verdadera originalidad -escribe- es de carácter colectivo y social" y estaría en su "sovietismo sui generis" ${ }^{11}$.

Un análisis de estos comentarios iniciales podría llevar a dictaminar un rechazo esencialmente político o incluso sobre bases nacionales. Pero las cosas son más complejas... En realidad, la recepción del constitucionalismo social alemán en Francia se verá atrapada en una doble tensión entre las viejas teorias del Estado del Kaiserreich, tan despreciado por la doctrina publicista de la Tercera República, y el reconocimiento constitucional de los nuevos derechos, "sociales", que parecen, sobre todo, promovidos por las fuerzas socialistas.

\footnotetext{
${ }^{9}$ René Brunet, La Constitution allemande du 11 août 1919, Payot, Paris, 1921, p. 324-325. Sobre Brunet, ver Carlos M. Herrera, "Etre socialiste en Faculté de droit. Quelques parcours sous la Troisième République", Recherches socialistes, n 50-51, janvier-juin 2010, p. 53-70.

10 Joseph-Barthélemy, "Préface ", a R. Brunet, La Constitution allemande..., op. cit., p. XI, p. XVII.

11 Edmond Vermeil, La Constitution de Weimar et le principe de la démocratie allemande, Istria, Estrasburgo, 1923, pp. 372-373. También afirma que "la única victoria que ha significado la Constitución de Weimar fue para este socialismo moderado que pretende completar la revolución politica con medidas socialistas y repudiar el marxismo revolucionario". Incluso vio en los "derechos económicos fundamentales", una realización del antiguo programa de Erfurt del SPD (p. 389). Sobre esta cuestión, v. Carlos M. Herrera, "El Estado, el derecho, el compromiso. Comentarios sobre las concepciones politico-legales de la socialdemocracia en Weimar" (1998) y "La socialdemocracia y el Estado de derecho en Weimar" (2001), ambos en traducción española en Carlos M. Herrera, Derecho y socialismo en el pensamiento jurídico, Universidad Externado de Colombia, Bogotá, 2002 y C. M. Herrera, "Constitution et social-démocratie. Pour une périodisation", en C. M. Herrera (ed.), Les juristes de gauche sous la République de Weimar, París, Kimé, 2002, pp. 27-48.
} 
Esta tensión se hace evidente cuando se abordan las ideas de Léon Duguit, el jurista francés que más había desarrollado la teoría social del Estado desde finales del siglo XIX. Como sabemos, el fundamento de todo derecho residia para él en la "solidaridad social", ese "hecho permanente, siempre idéntico a sí mismo", en el cual reconoce "el elemento constitutivo irreducible de cualquier grupo social" ${ }^{12}$. A partir de los argumentos de Durkheim, Duguit sostenía que "toda sociedad implica solidaridad; toda regla de conducta de los hombres que viven en sociedad ordena que se coopere en esta solidaridad; todas las relaciones humanas siempre han sido y siempre serán relaciones de similitud o división del trabajo; de ahí la permanencia de la regla de derecho y su contenido general ${ }^{13}$. Pero su originalidad se basa en el despliegue de esta relación social dentro del mecanismo estatal. El concepto de servicio público, mediante el cual Duguit buscaba definir el Estado, expresaba esta preocupación ya que es definido como "cualquier actividad cuyo cumplimiento deba ser asegurado, reglado y controlado por los gobernantes, porque el cumplimiento de esa actividad es indispensable para la realización y el desarrollo de la interdependencia social y es de tal naturaleza que únicamente puede ser realizada completamente mediante la intervención de la fuerza gobernante".

Tal concepción hacía posible, en particular, la intervención estatal en asuntos económicos y sociales, puesto que los gobernantes "no solo están obligados a abstenerse; están obligados a actuar, y esta obligación se refleja en el deber jurídico de educación, de garantizar el trabajo". Pero el jurista bordelés habia atacado, desde su primer libro importante, a aquel neo-individualismo que quería limitar el poder del Estado, en particular porque se mostraba incapaz de "fundar las obligaciones activas que le incumbe". Como resultado de la solidaridad social, hay una serie de imposiciones para el Estado, que está así "jurídicamente obligado a hacer ciertas leyes, y en particular, a organizar y asegurar por sus leyes la enseñanza, la asistencia y el trabajo". Por cierto, descarta, por inexacta, la idea de "derechos subjetivos a prestaciones positivas" los "derechos sociales", se diría hoy en día-, pero el Estado, en cualquier forma política que esté organizado, tiene deberes sociales para permitirle al individuo que necesita trabajar para vivir estar protegido contra la explotación, tener un seguro médico, medios de subsistencia además de un mínimo de cultura intelectual para todos. En otras palabras, "unas reglas de derecho que es obligatorio formular y aplicar", puesto que conducen a dar "a todos la posibilidad material y moral de colaborar en la solidaridad social ${ }^{14}$.

No es casual que el nombre de Duguit aparezca como una referencia para los juristas alemanes más cercanos a la socialdemocracia en Weimar, quienes veían

\footnotetext{
${ }^{12}$ Léon Duguit, Traité de droit constitutionnel, Boccard, Paris, 3e éd., t. II, 1927, p. 86.
}

13 Léon Duguit, Manuel de droit constitutionnel, 4e édition, Paris, Boccard, 1923, p. 11. Básicamente, la solidaridad "bien entendida", "es solo una coincidencia permanente de objetivos individuales y sociales", el hombre solo puede querer solidaridad (Léon Duguit, L'Etat, le droit objectif, et la loi positive, Fontemoing, Paris, 1901, p. 615). Sobre la dificultad del concepto de solidaridad en clave constitucional, ver Carlos M. Herrera, "La solidaridad y sus problemas politicoconstitucionales", Revista de Estudios Sociales, n 46, mayo-agosto 2013, pp. 63-73.

${ }^{14}$ Léon Duguit, Le droit social, le droit individuel et la transformation de l'Etat (1908), Paris, Alcan, 1922, p. 65 ; Manuel..., op. cit., p. 214, p. 299-300 ; Traité de droit constitutionnel, op. cit., t. III, 1928, p. 641. 
en el jurista francés al representante de una concepción social que buscaba, según Gustav Radbruch, establecer una preeminencia del derecho público sobre el derecho privado, con el objetivo de garantizar la protección económica de los individuos más vulnerables económicamente. Ya sea en un plan metodológico (este sería un enfoque que parte "de la sociedad para llegar al individuo, desde el derecho objetivo para llegar al derecho subjetivo, desde la regla social para llegar al derecho individual»), ya sea a nivel teórico ("el hombre, ser naturalmente social, está por esto mismo sujeto a una regla social que le impone obligaciones hacia los demás hombres, y [...] sus derechos se derivan únicamente de sus obligaciones, los poderes que tiene que cumplir libre y plenamente sus deberes sociales"), la tesis de Duguit procuraba establecer que la regla social se impone al individuo. En realidad, que dijera que la denominación "concepción socialista del derecho" era la que correspondería major para señalar su oposición a la visión individualista, no lo ponía en un sentido igualador tan claramente como Radbruch quería ver ${ }^{15}$.

Sea como fuere, Duguit era sin duda alguna el constitucionalista francés que podría explorar mejor esta constitución social. Sin embargo, cuando se ocupan tardiamente de ella, se contenta con seguir por la brecha ya abierta por JosephBarthélemy. Cuando el catedrático de Burdeos examina la Constitución de 1919, lo primero que señala es que el sistema bismarckiano refuerza el centralismo.

Duguit, por cierto, no puede ignorar el Consejo Económico del Reich en la tercera edición de su Tratado, aunque más no fuera porque Francia se acababa de dotar de un Consejo Económico Nacional en 1925. Estudiando el precedente alemán, Duguit señalaba que el poder de la iniciativa era muy avanzado, hasta el punto de que solo bastaría un pequeño paso para transformarlo en un verdadera "asamblea política, con derecho de decisión". Esta observación, en un momento en que estaba claro en Alemania que el Consejo Económico no había cumplido sus promesas y estaba cerca de la parálisis debido a la actitud de los patrones, era sintomática de una mirada distanciada... Tampoco aquí, Duguit parecia tener para ofrecer un análisis específico, y se contentaba con seguir los juicios de la tesis doctoral de Marcel Prélot.

El trabajo de Prélot no era la primera tesis que se defendía en las facultades de derecho francesas sobre el art. $165^{16}$, pero se impuso por la agudeza de su aspecto comparativo, y la fuerte personalidad del autor. No podemos dar cuenta de todos los ecos que encierra será suficiente enfatizar dos inflexiones importantes con respecto a las primeras reacciones doctrinales. La primera tiene que ver con el fondo: Prélot acentúa en su análisis del Consejo económico la idea corporativa, un componente que estuvo presente en el inspirador de la norma en la asamblea constituyente, Hugo Sinzheimer, quien no dudaba en hablar de "comunidad de

\footnotetext{
${ }^{15}$ Léon Duguit, Manuel..., op. cit., p. 6. Duguit había aclarado, ya antes de la Gran guerra, que no se refería a un partido político o a un programa cuando usaba ese término. Cf. Léon Duguit, Les transformations générales du droit privé depuis le code Napoléon (1912), Paris, Alcan, 1920, p. 8-9.

${ }^{16}$ Ya en 1922, G. Doublet de Persan dedicaba su tesis al Sistema de Consejos Económicos en Alemania. Aunque tenía un carácter principalmente descriptivo, la investigación tuvo el mérito de vislumbrar la pérdida de eficacia económica del sistema, que evolucionaba para él hacia una forma de federalismo.
} 
trabajo". La segunda, con la óptica: como especialista de derecho público Prélot reconstruía la problemática a partir de la vieja cuestión de la representación política -esa tercera cámara que estaba en la mente de muchos especialistas desde comienzos del siglo XX- más que de los derechos sociales. Pero no dejaba de observar que "el intervencionismo económico o social presenta con la representación profesional una estrecha correlación, tanto histórica como racional ${ }^{17}$.

\section{II}

Para una recepción general del constitucionalismo social que ponga el acento en los derechos sociales, será necesario esperar hasta la segunda mitad de la década de 1920. La aclimatación será llevada a cabo por un jurista bastante marginal en el panorama universitario francés, Boris Mirkine-Guetzevitch. Este emigrado de origen ucraniano establecido en París después de la Revolución bolchevique, no era un pensador realmente original en estos asuntos, pero, como constitucionalista, su trabajo de reconstrucción insistía en las perspectivas históricas y comparativas.

Así, en la sintesis del constitucionalismo europeo de entreguerras que se proponía realizar a finales de la década de 1920, la cuestión social ocupaba para él un «lugar prominente». En particular, Mirkine enfatizaba que la técnica constitucional de las declaraciones de derechos, inaugurada según él por la Revolución Francesa, y mediante las cuales el Estado se veía obligado a respetar y garantizar los derechos del hombre, era ampliada por "la concepción solidarista de las libertades individuales", que establecía la existencia de un deber objetivo del Estado.

Así, el derecho constitucional de posguerra reconocía nuevos derechos sociales, fundados en el "ciudadano social", llevando de este modo a la instauración de obligaciones positivas para el Estado. De hecho, según Mirkine, "todos los problemas de la vida social [...] ahora se convierten en derechos del hombre y del ciudadano". Este es el caso de las normas constitucionales que contemplaban la protección de la familia, la educación pública, la organización de la vida económica y la concepción de la propiedad como una función social.

Esta "tendencia", como él la llamaba, sería parte de un movimiento más amplio de racionalización del poder que, en su opinión, caracterizaría ese nuevo constitucionalismo. Más exactamente, seria una de estas formas, por la cual "el derecho penetra en todos los fenómenos de la vida social», pero sobre todo, busca "crear un mínimo de condiciones jurídicas que permitan asegurar la independencia social del individuo". Y para ilustrar su idea, reproducía nada menos que 24 artículos de la segunda parte de la Constitución de Weimar, entre el art. 119, que abría la sección dedicada a "La vida social", y el art. 165.

Aunque observaba que el desarrollo de los derechos sociales se relacionaba a la fuerte presencia de elementos de izquierda en las asambleas constituyentes de

\footnotetext{
${ }^{17}$ Marcel Prélot, La Représentation professionnelle dans la Constitution de Weimar et le Conseil Economique National, París, Spes, 1924, p. 65. Sobre esta obra, v. Pierre-Henri Prélot, "Weimar dans la pensée démocratique de Marcel Prélot. Etude d'après sa thèse de doctorat sur la représentation professionnelle dans la Constitution de Weimar", en Carlos M. Herrera (ed.), La Constitution de Weimar et la pensée juridique française, Paris, Kimé, 2011, pp. 53-91.
} 
los diferentes países, como en Alemania en 1919, Mirkine-Guetzevitch intentaba separarlos de un origen estrictamente político, enfatizando que habían sido de todas maneras constitucionalizados aún en ausencia de los socialistas en esos congresos o sin una representación determinante, dando el ejemplo de varios países de Europa oriental. De hecho, según él, el surgimiento de la cuestión social en las asambleas constituyentes se debió, por un lado, a la crisis económica, y por el otro, a la experiencia -"amenazante»- de Rusia ${ }^{18}$.

Cuando Mirkine-Guetzévitch publicó estos análisis, estaba claro que la efectividad práctica de estos derechos sociales era limitada, pero eso no afectaba, en su opinión, al "valor teórico" de su reconocimiento en un texto constitucional, no solo porque actuaba como un principio educativo efectivo desde el vamos, sino también como manifestación de una tendencia que debía realizarse cada vez más en el futuro.

Mirkine-Guetzevitch colocaba esta evolución bajo el signo del solidarismo jurídico teorizado por Duguit, pero tendia a precisar la idea de "deberes objetivos del Estado" bajo la forma de obligaciones positivas, por la idea de "derechos sociales" (y no ya como "deberes", como en la concepción de aquel que nuestro autor reivindicaba como uno de sus maestros).

Esta tendencia se expresaba por un doble sesgo: la defensa social de la persona en las nuevas declaraciones, bajo la forma de derechos sociales, y la limitación, en nombre de los intereses sociales, de ciertos derechos, incluido el derecho de propiedad, lo que el jurista de origen ruso denominaba el control social de las libertades individuales. "Bajo la influencia de las complejidades de la vida moderna, además de la extensión del contenido material de las Declaraciones de Derechos, el derecho contemporáneo introduce una serie de limitaciones esenciales de carácter social, cuyas aplicaciones prácticas redundan en el bienestar de los individuos". Aunque este criterio de control social se reflejaba ya en el espíritu de las Declaraciones de Derechos, debería sobre todo conducir a la adopción de una legislación democrática ${ }^{19}$.

Poco después encontraremos otra recepción del constitucionalismo social, aunque de signo especulativo. En efecto, tendrá lugar en el ámbito de la filosofia del derecho y será promovida por otro emigrante ruso, Georges Gurvitch, que tenía muchos puntos de contacto con Mirkine, incluso personales. La ambición de esta tentativa era muy amplia e iba más allá del del campo constitucional e incluso del jurídico, entroncando con una preocupación tanto política como

\footnotetext{
${ }^{18}$ Estas ideas que serán desarrolladas por Georges Burdeau en su libro Le régime parlementaire dans les constitutions européennes d'après-guerre, Editions internationales, París, 1932, p. 45 y sq.

19 Boris Mirkine-Guetzévitch, Les nouvelles tendances du droit constitutionnel, Giard Paris, 1931, p. 88-89, p. 114. El libro reproducía una serie de artículos publicados en la Revue du Droit Public, entre los años 1928 et 1929, y un informe que había presentado ante el Institut international de Droit public que habia creado. De hecho, se expresaba en la misma dirección en Les Constitutions de l'Europe nouvelle, Delgrave, Paris, 1930 ( $\left.2^{\mathrm{e}} \mathrm{ed}\right)$.
} 
filosófica ${ }^{20}$. Pero la categoría de derecho social le permitía teorizar los logros constitucionales del sistema weimariano.

$\mathrm{Si}$, para Gurvitch, desde un punto de vista general (politico), el derecho social era siempre un derecho de integración, incluso de cooperación, buscaba distinguir conceptualmente tres tipos de estatuto diverso. El primero de ellos, en todo los sentidos de la palabra, era el "derecho social puro e independiente", espontáneo pero equivalente o incluso superior al derecho estatal. Una variante más restringida lo formaba el "derecho social puro", pero "sujeto a la tutela del Estado", que se desplegaba más bien en el campo del derecho privado. Ambas variantes expresaban la oposición de la sociedad al Estado, y eran, sobre todo, extra-legislativas y extra-estatales, aunque apoyándose en autoridades que no resultaban menos "objetivas". Finalmente, Gurvitch identificó una tercera posibilidad, el "derecho social anexado por el Estado", que tenía rango de derecho público ${ }^{21}$.

En realidad, solo un derecho social puro podría mostrarse "capaz de penetrar en el interior mismo de la fábrica y de la empresa y limitar la arbitrariedad de los patrones". Así, el derecho obrero se afirmaba como un derecho social "puro e independiente", por el creciente papel que tenian en su elaboración las "agrupaciones espontáneas de los interesados y sus acuerdos». En la época contemporánea, dicho derecho encarnó mejor el desarrollo de este derecho social extra-estatal y espontáneo, que a su vez dio a los miembros de la institución una posición estatutaria, pero siempre mantuvo un carácter antijerárquico e igualitario.

Gurvitch insistia en que bajo el sistema weimariano este derecho tenía las características de un derecho constitucional laboral (Arbeitsverfassungsrecht) o un derecho constitucional de la empresa, heredero de la vieja cuestión de la "fábrica constitucional" que se había desarrollado dentro del liberalismo social alemán de finales del siglo XIX, pero rebasándolo. Gurvitch encontraba esa superación en instituciones como el convenio colectivo de trabajo y, especialmente, en los consejos de las fábricas y los consejos económicos, de lo cual Weimar ofrecía una consagración constitucional por primera vez en la historia. Estos consejos y su derecho -así como la idea de Arbeitgemeinschaft avanzada por la doctrina alemana cercana a los socialistas para definir la institución del art. 165- representaban la principal expresión de aquel "derecho social puro", que se situaba del lado de la sociedad y contra el Estado.

Sus juicios, en todo caso, se apoyaban en un conocimiento del pensamiento jurídico alemán del siglo XIX de primera mano, de Lorenz von Stein a Otto von Gierke, a quien consideraba por el teórico más importante del derecho social alemán -Gurvitch, quien había hecho parte de sus estudios universitarios en Alemania, primero emigró a ese país en 1920, antes de establecerse en Francia-. Pero mostraba también un dominio muy fino de la doctrina del derecho laboral alemán, de Philipp Lotmar a Hans Nipperdey, pasando por autores como Walter Kaskel, Georg Flatow, Edwin Jacobi o Clemens Norpel. Dentro de los juristas

\footnotetext{
${ }^{20}$ Ver. Carlos M. Herrera, "Droits sociaux et politique chez Georges Gurvitch", Droit et société, n 94, 2016, p. 513-524.

${ }^{21}$ Georges Gurvitch, Le temps présent et l'idée de droit social, París, Vrin, 1932, p. 10.
} 
laboristas weimarianos, Gurvitch ponía de relieve la figura de Hugo Sinzheimer, a quien atribuía no solo una orientación anti-formalista particularmente importante, sino que también le daba el título de "teórico más destacado de los derechos de los trabajadores". Munido de estas credenciales, tomará su trabajo como un paradigma del desarrollo de los derechos de los trabajadores en su tesis complementaria sobre La idea del derecho social, donde destaca los pasajes del manual de Sinzheimer en derecho laboral, los Grundzüge des Arbeitsrechts, en el que el derecho obrero aparece como un derecho autónomo, engendrado por los grupos sociales auto-organizados, pero tan objetivo como la ley. Al interior de la doctrina de Sinzheimer, es la idea de convenio colectivo de trabajo que le sirve de hilo conductor para su reconstrucción; más precisamente, el principio general de su creación por la autonomía del grupo.

En el mismo sentido, Gurvitch ve en la concepción de los consejos de Sinzheimer una expresión del derecho social puro e independiente del Estado, acercándolo a las "geniales visiones de Proudhon", principalmente, su discurso en la constituyente de Weimar en junio de 1919 en la que el jurista alemán opone la Wirtschaftsverfassung a la Staatsverfassung. "Así, el Sr. Sinzheimer, al extraer las últimas consecuencias de todo el desarrollo de las instituciones y las recientes doctrinas del derecho obrero, ha tomado a sabiendas como guía de sus comentarios sobre el "derecho constitucional de la empresa", la idea del derecho social puro e independiente, un derecho que brota de la incipiente organización de la Sociedad económica opuesta al Estado, con quien entra en competencia, alzándose ante él como un contrapeso" ${ }^{22}$.

De hecho, para Sinzheimer, "las fuerzas sociales libremente organizadas producen y administran automáticamente un derecho objetivo directo y sistemático". En este sentido, "el derecho laboral», decía en junio de 1922 en el congreso de la ADGB -la Central Obrera Socialista, con mucho, la de mayor número de miembros-, "en su desarrollo, en su contenido, en su perfeccionamiento está vinculado, en última instancia, a las fuerzas económicas y espirituales de la vida social»" ${ }^{23}$.

Antes de la Constitución de 1919, y después de los trabajos de Lotmar, Sinzheimer teorizó la idea de convenio colectivo de trabajo (Tarifvertrag). Era esta institución la que mejor expresaba la naturaleza social del derecho obrero porque en el convenio colectivo, "las masas se autodeterminan jurídicamente y se autorregulan". La institución estaba estrechamente vinculada a los sindicatos, porque "un derecho tarifario solo puede existir si las organizaciones actúan como su órgano efectivo. Estas son el vínculo entre las masas y el derecho" ${ }^{24}$. Sinzheimer habia distendido el concepto para producir un modelo, en esa época todavia fragmentario, de democracia industrial, que tendía a coincidir con la tradición del socialismo de las guildas inglés.

Retengamos, empero, la dimensión jurídica. Es, por tanto, la autodeterminación la que define el derecho obrero; este carácter social hace que

${ }^{22}$ Georges Gurvitch, Le temps présent et l'idée de droit social, op. cit., p. 82-83.

${ }^{23}$ Hugo Sinzheimer, Ein Arbeitstarifgesetz. Die Idee der sozialen Selbstbestimmung im Recht, Berlin, Duncker \& Humblot, 1916, p. 186, Hugo Sinzheimer, Das zukünftige Arbeitsrecht in Deutschland, Berlin, 1922, p. 2.

${ }^{24}$ Hugo Sinzheimer, Ein Arbeitstarifgesetz, op. cit., p. 32, p. 36. 
el derecho colectivo triunfe sobre el derecho individual, que "se levante contra el poder de los patrones que resulta de las relaciones de propiedad, el orden social de las relaciones de las personas ${ }^{25}$. El fundamento del derecho obrero radica en una concepción social del derecho, que propugna la idea del desarrollo, la creación y administración de un derecho objetivo por parte de las fuerzas sociales libremente organizadas, o, en otras palabras, la autodeterminación social en el derecho. Por esta vía, el derecho laboral lleva a Sinzheimer hacia una filosofía social del derecho. Según él, de hecho, "el derecho social no solo conduce a un nuevo contenido del derecho, sino también a un nuevo tipo (Art) de pensamiento jurídico". Frente a un derecho esencialmente estático, el derecho social aparece como un derecho dinámico, que concibe a la sociedad como un "proceso social de la vida". Al mismo tiempo, esto empuja a una crítica del carácter abstracto de la categoría de persona ya que, como escribe: "Las personas son iguales, los seres humanos no lo son". El derecho social entiende al hombre no como persona, sino como ser social, con su existencia real. No es casualidad que esta filosofia adquiera los rasgos de una antropología, proponiendo un nuevo concepto de hombre. En este estadio, la tarea del derecho social no es la autodeterminación, sino la determinación social ${ }^{26}$. La sociedad no es "naturaleza", sino un objeto sujeto a la configuración humana. La politica regresa aquí: Sinzheimer amplía esta idea al vincular las relaciones en el mundo del trabajo con el problema de la democracia. Su pensamiento presenta asi otra faceta, que podría ser presentado como una filosofia política del trabajo.

Resulta sorprendente observar que Gurvitch no mencione en ningún momento el fuerte compromiso socialista de Sinzheimer, apenas si recuerda su trabajo como redactor del art. 165. A que se debía ocultar algo tan evidente ¿ Una preocupación excesiva tal vez por establecer la cientificidad de la noción de derecho social en una tesis doctoral? Sinzheimer era uno de los principales juristas de confianza de los sindicatos socialistas, que incluso habian planeado hacerlo nombrar ministro de trabajo. En cualquier caso, parece dificil entender su visión de "comunidad de trabajo" separada de su compromiso político con el socialismo alemán, cercano a la central obrera. Es cierto que la idea aparece muy temprano en Sinzheimer, bastante antes de su tardía afiliación a la SPD mayoritaria, que sólo se materializa durante la guerra, puesto que el jurista afirmaba que el propósito fundamental de cualquier acuerdo colectivo es "el establecimiento de una comunidad de derecho y de paz en el campo laboral». En su famoso discurso ante la Asamblea Nacional, en junio de 1919, argumentaba que "hay en la vida económica tanto la oposición como la comunidad. La oposición, que no puede ser ignorada, es la del capital y el trabajo". El capital ya contaba con su representación, materializada especialmente en las cámaras de industria. Era necesario pues brindar otra para todos los trabajadores y empleados. "La misión de esta representación debe ser expresar todos los intereses de la clase obrera como tal, de manera ordenada, a través un organismo público". Estos consejos de fábrica conformarían "una representación unilateral

${ }^{25}$ Hugo Sinzheimer, Grundzüge des Arbeitsrechts, 1927, p. 60 (cit. en Georges Gurvitch, Le temps présent et l'idée de droit social, op. cit., p. 21).

${ }^{26}$ Hugo Sinzheimer, "Der Wandel im Weltbild des Juristen" (1928), ahora en Hugo Sinzheimer, Arbeitsrecht und Soziologie, Gesammelte Aufsätze und Reden, Europäische Verlagsanstalt, Frankfurt del Meno, 1976, t. II, p. 42-43, p. 47-48. 
de intereses", que apuntaría "a aumentar y realizar de la influencia económica de la clase obrera". Pero también existía una comunidad "basada en el interés de los patrones y los trabajadores en la producción". Los Consejos Económicos "deben satisfacer los intereses de producción" al "colaborar [...] con todos los elementos involucrados, para aumentar la productividad, reducir los costos de producción y ajustar la producción en la medida de lo posible sobre la base de consideraciones sociales". Esta visión moderada reconcilia el papel de los sindicatos con la idea de los consejos de fábrica, que tenían raíces más bien bolcheviques.

Para Sinzheimer, este derecho de colaboración reconocido por el art. 165 se había convertido en un "derecho fundamental de la clase obrera", como lo escribe más tarde, al cumplirse diez años de la promulgación de la Constitución ${ }^{27}$. Incluso después de que Hitler llegara al poder, Sinzheimer seguía explicando que la comunidad de trabajo estaba destinada a "integrar a los trabajadores y a los patrones en una organización única", cuya tarea era "controlar y dirigir la administración de cada empresa, de acuerdo a puntos de vista comunes", contribuyendo así "al desarrollo de un orden industrial basado en un sistema de convenciones colectivas" ${ }^{28}$.

La institución de la convención colectiva se insertaba con la idea de que "la lucha de clases no es un fin, sino un medio". En los primeros años de la República, Sinzheimer defendió la vieja concepción de E. Bernstein del socialismo no como una idea o un fin, sino como un movimiento. Por entonces, enfatizaba que la politica de la clase obrera debía ser, especialmente en tiempos de crisis, politica popular, "la lucha por la preservación y liberación del pueblo" ". Esta posición se expresaba en un contexto optimista sobre la evolución de la Constitución, y especialmente de las relaciones sociales, en el que Sinzheimer cree poder avanzar la tesis, al menos con respecto a la legislación laboral, de que "vivimos en una situación de transición, intermedia (Übergangszustand). Ya no estamos completamente en el capitalismo privado, pero aún no somos socialistas", como afirmaba en su discurso en el congreso de la ADGB de $1922^{30}$.

Ciertamente, diez años después de la promulgación de la Constitución, los resultados distaban de ser concluyentes, y en el informe que preparó para la Central de trabajadores socialistas una comisión de intelectuales coordinada por Fritz Naphtali, y en la que Sinzheimer se encarga de redactar el capítulo jurídico, no quedaba más remedio que constatar el fracaso de la colaboración de clase para dirigir la economía. Por supuesto, la inserción de fuerzas sociales que habían sido anteriormente marginadas no dejaba de producir algunos efectos, pero resultaban insuficientes para conducir al socialismo a través de la

${ }^{27}$ Fritz Naphtali (ed.), Wirtschaftsdemokratie. Ihr Wesen, Weg und Ziel (1928), Frankfurt del Meno, Europäische Verlagsanstalt, 1968, p. 147.

${ }^{28}$ Hugo Sinzheimer, "La théorie des sources du droit et le droit ouvrier", Annuaire de l'Institut International de Philosophie du droit et de sociologie juridique, 1934, p. 75.

${ }^{29}$ Hugo Sinzheimer, "Grosse Koalition" und Sozialdemokratie, Frankfurt, 1922, p. 5, p. 8. En este sentido, defendía con su intervención una politica de gran coalición, que promovía la alianza en el gobierno del Reich del SPD con la Deutsche Volkspartei, concebida como el representante politico de las organizaciones de la gran industria. La "gran coalición" se vio entonces como una traducción política del acuerdo social prevista por el art. 165.

${ }^{30}$ Hugo Sinzheimer, Das zukünftige Arbeitsrecht in Deutschland, op. cit., p. 2. 
democratización de la economía. Esto condujo a la revalorización de la "primacía del Estado como defensor de los intereses generales de la economía nacional». El nuevo programa de la ADGB, adoptado entonces, presentó el proyecto de transformación como una ruptura con el Estado autoritario al nivel de las relaciones económicas, una democratización en definitiva, que subordinaba cada actividad económica a los intereses de la comunidad (Allgemeinheit), un proceso en el cual el Estado democrático, entendido como Gemeinwesen, se convierte cada vez más en el medio ${ }^{31}$.

\section{III}

Aunque se da en un contexto de crisis para la República de Weimar, la publicación de las tesis de Gurvitch en 1932 representó la recepción más amplia del constitucionalismo social en Francia. Pero el trabajo contaba con una serie de peculiaridades que condicionaban su propia recepción en el campo jurídico. En primer lugar, Gurvitch, aunque no era del todo un marginal en la institución universitaria, todavía se encontraba en una posición académica inestable y endeble, que intentó fortalecer invirtiendo en empresas colectivas más concretas, como la creación de los Archives de philosophie du droit et de la sociologie juridique, por entonces órgano de una sociedad cientifica que tenía a nuestro autor como iniciador, el Institut International de Philosophie $d u$ Droit. Ambas instituciones pronto se convertirán en el vector de la recepción de ideas de aquellos juristas alemanes que, como Radbruch y Sinzheimer, habian sido obligados a abandonar sus cátedras poco después de la llegada de Hitler al poder, $\mathrm{y}$ cuyos escritos aparecen por primera vez en francés ${ }^{32}$. Pero Gurvitch no era ni constitucionalista ni jurista en el sentido estricto del término: era un filósofo, cada vez más interesado en la sociología jurídica. En última instancia, cuando su primera tesis sobre el derecho social aparece en 1932, es recibida con un interés distante en la Facultad de Derecho, sin que esto conduzca realmente a apropiarse de sus ideas -la gran abstracción que expresaban podian alejarlas aún más de las mentes de los juristas.

Pero es sobre todo la reacción de Sinzheimer a las ideas de Gurvitch que ilustra los límites teóricos de esta recepción ${ }^{33}$. Gurvitch, en buen adepto de Proudhon, siempre desconfiará de la intervención estatal en asuntos sociales, y es sobre el lugar del Estado donde surgen los desacuerdos con su "amigo" Sinzheimer. Es este último quien se encargará de puntualizar las diferencias en una serie de escritos. El contexto del intercambio es importante. Sinzheimer no

${ }^{31}$ Fritz Naphtali (ed.), Wirtschaftsdemokratie, op. cit., p. 39-41, p. 25.

${ }^{32}$ En su primer año, los Archivos publican una traducción de G. Radbruch sobre derecho social, que será seguida posteriormente por otros textos. Gurvitch también dedica un estudio al pensamiento de Radbruch: "Una filosofía antinómica del derecho", en el número de 1932. Sobre la Teoría del derecho social de Radbruch, ver Carlos M. Herrera, "Entre filosofía del derecho y socialismo: el concepto de derecho social en Gustav Radbruch", en J. L. Guzmán Dálbora, P. König (eds.), Gustav Radbruch: penalista, filósofo, humanista, Olejnik, Santiago de Chile, 2018.

33 Llegamos quizás al momento conceptual más importante de la recepción de ideas socioconstitucionales en Francia. Pero también se podría hablar de recepción "teórica" en el sentido de supuesta, imaginaria o dudosa, porque, a pesar del interés, la controversia en sí misma no tuvo el menor eco en las escuelas de derecho. 
solo se vio obligado a dejar su puesto de profesor honorario en la Universidad de Frankfurt, sino que, esta vez en su calidad de judio, prefirió abandonar su país de origen para establecerse en los Países Bajos. Se convirtió, a partir de finales de 1933, en profesor de sociología del derecho en la Universidad de Ámsterdam. En ese momento, sus ideas, e incluso su persona, están muy presentes en Francia, siempre a instancias de Gurvitch ${ }^{34}$. Participó en la primera sesión del Institut International de Philosophie du Droit, que tuvo lugar en Paris en octubre de 1933, siendo designado como en uno de los vicepresidentes de la nueva institución. En esa ocasión, había pronunciado una conferencia sobre "La teoría de las fuentes del derecho y el derecho obrero", que aparece en el Anuario del Institut en 1934, y poco después publica un segundo texto en francés, sobre «El Estado y la sociedad en nuestro tiempo", en los Archives de Philosophie du Droit et de la Sociologie juridique. Ya en este último texto, revelaba sus diferencias con Gurvitch, que desarrollará con más detalle un año después, primero en idioma holandés, luego, en alemán, en el Zeitschrift für öffentliches Recht austriaco, con motivo de un largo estudio sobre la teoría del derecho social del pensador franco-ruso.

En términos generales, y desafiando la visión proudhoniana de la tesis de Gurvitch, Sinzheimer estimaba que no se podia concebir ningún "cuerpo social" sin una forma de dominación -la dominación no consistia solo en asegurar el propio interés-. Además, según el jurista alemán, "las fuerzas no estatales no pueden conducir por sí mismas" a una nueva unidad y, por lo tanto, "a nivel nacional, la unificación es imposible sin la intervención del Estado". Incluso si uno se coloca en una perspectiva federalista internacional, la comunidad "necesariamente descansa en una asociación concomitante entre los Estados". Por lo tanto, la autodeterminación social necesitaría del Estado al servicio de esta gestación de una comunidad autónoma ${ }^{35}$. Desde sus trabajos de la década de 1910, Sinzheimer argumentó que el Estado era el vínculo de una vida social unitaria, la autoadministración social en la ley no disuelve la relación con el Estado, sino solo la corrige ${ }^{36}$. Porque entre las funciones del Estado está la de equilibrar los diferentes intereses sociales. La participación del Estado es aún más decisiva cuando se plantea la cuestión desde un punto de vista económico, tanto en lo que respecta a la propiedad como a la producción.

Ciertamente, en su trabajo de la década de 1920, Sinzheimer insistió en que "las fuerzas estatales no son de ninguna manera suficientes para lograr la necesaria regulación del trabajo. El derecho estatal, demasiado rígido y

${ }^{34}$ Tal vez acarició la idea de establecerse en Francia. La idea sobrevoló en otros juristas alemanes cercanos a él, como G. Radbruch, que consideró la posibilidad de instalarse en Lyon, con el apoyo de Edouard Lambert, en quien otros refugiados encontrarian refugio, siempre a través de Gurvitch. Más tarde, Sinzheimer participará, a distancia, en una de las empresas intelectuales de los emigrantes alemanes en París, la Freien deutschen Hochschule. Como parte de la organización de los cursos, programados para el primer semestre de 1939, dictaria una asignatura sobre "Neue Fragestellungen in der Soziologie seit 1933". En el órgano del grupo, el Zeitschrift für freie deutsche Forschung, publica un texto por la muerte de Rudolf Stammler (marzo de 1939), que quedará inacabado por la interrupción de la revista, hasta su postrer publicación a título póstumo (Sinzheimer muere en 1945, tras haber vivido oculto en Holanda bajo condiciones penosas).

${ }^{35}$ Hugo Sinzheimer, "L'Etat et la société à notre époque", Archives de philosophie du droit et de sociologie juridique, 1934, p. 139.

${ }^{36}$ Hugo Sinzheimer, Ein Arbeitstarifgesetz, op. cit., p. 194, p. 190. 
demasiado esquemático, no siempre puede seguir el desarrollo de la sociedad, que es cambiante y variado". Para remediar este hecho, Sinzheimer había imaginado dar un lugar privilegiado al derecho autónomo producido directamente por los grupos sociales organizados. El resultado era un derecho autónomo, incluso no estatal, pero "aún dependiente del Estado" ${ }^{37}$ En 1916, escribió "no vemos ninguna diferencia entre el derecho coercitivo de la ley y el derecho coercitivo de la autonomía convencional (Vertragsautonomie). Ambos son un derecho objetivo" ${ }^{38}$. Sinzheimer habia argumentado, como lo recordaba Gurvitch en sus obras, que las instituciones de los trabajadores "son los soportes de un nuevo orden social, que se elevan por encima de los individuos y los integran en una totalidad, las primeras etapas de una nueva organización en formación, que necesita un derecho separado completamente independiente de la oposición entre el derecho público y el privado" ${ }^{39}$.

Pero la peculiaridad del pensamiento social es clasificar todo derecho, incluido el derecho privado, bajo el interés público. Por eso hablará de una constitución del trabajo (Arbeitsverfassung). De hecho, si "la comunidad entre el trabajo y la propiedad es una comunidad administrativa", el derecho que regula esa comunidad es dicha constitución del trabajo. "La organización de los consejos realiza la comunidad entre el trabajo y la propiedad en la empresa". En sus orígenes, fue una organización creada sin intervención estatal, pero en virtud de la Constitución de 1919 se convirtió en "una institución estatal. El derecho que lo regula es derecho público" ${ }^{40}$.

Como se puede apreciar, la pregunta clave para Sinzheimer era saber cómo el derecho social entraba en contacto con el derecho estatal y, más allá, el problema de su eficacia. En ese sentido, juzgaba que el Estado podría mostrar distintas actitudes ante ese derecho no estatal. Oponerse era, de hecho, una de ellas, pero también podía otorgar a este derecho una fuerza vinculante (como en el caso de la legislación de protección para los trabajadores), o incluso simplemente reconocerlo (especialmente con las reglas que derivaban de los convenios colectivos). Por el contrario, podría también someter el derecho no estatal (como lo hizo el Estado fascista italiano) o incluso suplantarlo (como lo hacia Alemania nazi).

Pero un derecho no estatal, como el derecho obrero, podría a su vez tener varias formas: una forma jerárquica (la supremacía del patrón sobre el trabajador, cuando no habia contrato de trabajo), una forma colectiva (cuando los trabajadores organizados contrataban colectivamente con el empresario, sin que se elimine un modo de subordinación), y finalmente una forma comunitaria (cuando las partes antagónicas forman un todo superior que regula la cuestión económica en su conjunto, y no solo la empresa). Fue esta forma la que quiso realizar el arte. 165 de la Constitución de Weimar, pero en 1934 su arquitecto declaraba su fracaso, que consideró retrospectivamente como "inevitable» en vista de las rígidas posiciones de cada una de las partes.

${ }^{37}$ Hugo Sinzheimer, Grundzüge des Arbeitsrechts, Fischer, Jena, 1927, p. 46.

${ }^{38}$ Hugo Sinzheimer, Ein Arbeitstarifgesetz, op. cit., p. 109-110. Para Sinzheimer, el acuerdo colectivo no es solo una relación legal sino también una fuente de derecho (p. 39).

${ }^{39}$ Hugo Sinzheimer, Grundzüge des Arbeitsrechts, p. 86.

${ }^{40}$ Hugo Sinzheimer, Grundzüge des Arbeitsrechts, op. cit ., p. 210-211, p. 214. 
En cualquier caso, el derecho social necesitaba del derecho estatal para alcanzar el elemento jurídico formal. Aunque Sinzheimer lo llamaba una "fuente secundaria", era fundamental para superar las desventajas de un derecho espontáneo, incapaz de superar por sí solo la arbitrariedad y el dominio. Por supuesto, cuando el Estado participaba en la formación de un derecho social como era el derecho obrero, estaba sujeto a modelos legales no estatales, como la empresa, el convenio colectivo o la comunidad. Pero el Estado podía también favorecer, con su intervención, la creación de nuevas instituciones, que estaban aún en ciernes en el derecho social, extra-estatal. "En todas estas hipótesis, el Estado se afirma a sí mismo como representante de la conciencia colectiva de unidad, es decir, la conciencia de que las fuerzas autónomas de la sociedad necesitan equilibrio y deben armonizarse». En otras palabras, la fuente estatal, aunque presente un carácter secundario, es "tan indispensable desde el punto de vista social" como lo son las fuentes primarias no estatales. Al menos en un Estado "consciente del valor creativo del derecho no estatal", que solo intervendrá después de constatar la impotencia del derecho no estatal para alcanzar su objetivo, es decir, un Estado democrático.

Dos años después, Sinzheimer insiste aún más en este punto de vista y considera que es incorrecto creer que el Estado tiene un papel secundario en la creación del derecho. "En efecto, no podemos calificar como "social" la única integración libre de las fuerzas sociales, sino también la integración estatal " ${ }^{41}$. Autonomía y estatismo no se excluyen a priori, al contrario. Para imaginar, como lo hacía Gurvitch, una creación puramente no estatal del derecho, "todas las oposiciones de intereses" debian ya estar superadas, haciendo que las "fuerzas sociales autónomas" estuviesen "directamente dirigidas hacia la afirmación de unidad del todo social». En otras palabras, "habrian integrado en su propia conciencia el propósito del Estado" ${ }^{42}$.

En última instancia, para Sinzheimer, Gurvitch "ignora el papel que juega el estado en la estructura de la vida social ${ }^{43}$. Y como había escrito poco antes, el concepto de derecho social no podia ser alcanzado por consideraciones abstractas, sino por "fijaciones históricas" (geschichtlichen Feststellung).

Gurvitch responderá insistiendo en la posibilidad de un derecho social independiente. Aunque admite que Sinzheimer tiene razón acerca de la dificultad de su desarrollo en el sistema capitalista, encontraba sin embargo restos del pensamiento de Lorenz von Stein en sus posiciones, incluida la idea de que el Estado siempre sería representativo del interés general. En la década de 1940, la crítica de Gurvitch se extendió al propio modelo constitucional weimariano, juzgado demasiado alejado de la idea de derechos, basados en la libertad y la dignidad del ser humano, y más cercana a "los programas y promesas de la legislación social del Estado", lo que podría explicar el cambio hacia un modelo estatista e incluso corporatista ${ }^{44}$.

\footnotetext{
${ }^{41}$ Hugo Sinzheimer, "Eine Theorie des sozialen Rechts", op. cit., p. 186-187.

${ }^{42}$ Hugo Sinzheimer, "La théorie des sources du droit et le droit ouvrier", op. cit., p. 78.

${ }^{43}$ Hugo Sinzheimer, "Eine Theorie des sozialen Rechts", op. cit., p. 186.

${ }^{44}$ Georges Gurvitch, La Déclaration des droits sociaux (1946), Dalloz, Paris, 2009, p. 36, p. 44.
} 
Quizás existiese la tentación por resumir los términos de la polémica en la oposición entre una concepción política del derecho, como la encarnada por Sinzheimer, y una visión más especulativa y abstracta, como la que representaba Gurvitch $^{45}$. Sinzheimer parece sacar conclusiones sobre todo en un plano metodológico, ya que como afirma con ingenio una "teoría del derecho social sólo podrá alcanzar su plena fructificación se continúa en una teoría social del derecho" (p. 187). Contra el formalismo legal, reivindicaba un método sociológico para el conocimiento del derecho, que no se limitara a las normas jurídicas, sino que partiera de "formas jurídicas concretas de la vida social ${ }^{46}$. En este sentido, el carácter social del derecho no era lo social en sí mismo, sino los fenómenos sociales que se producen en las dinámicas de las formas jurídicas burguesas en la sociedad capitalista ${ }^{47}$. Sin embargo, hay otros ingredientes que intervienen en este desacuerdo y que nos devuelven a las condiciones de recepción de las ideas weimarianas en Francia.

Como hemos visto, la tradición que podría ser más favorable a la inclusión de normas sociales en el derecho constitucional, que se construyó en torno del pensamiento de Léon Duguit antes de la Gran guerra, era sobradamente ajena a la idea de "derechos" sociales, ya fueran reconocidos a las personas o a los $\operatorname{colectivos}^{48}$. La recepción más completa después de la Primera guerra mundial, la de Georges Gurvitch, desconfiaba demasiado de la idea de Estado ${ }^{49}$. Entre las dos posiciones, la originalidad del dispositivo alemán se perderá.

Esta recepción frustrada, sin embargo, deja al descubierto el Sonderweg del constitucionalismo social alemán. En una cultura jurídica y politica que ya tenía una fuerte tradición (burguesa) de Estado benefactor, con el modelo defendido por L. v. Stein y, sobre todo, con los logros prácticos alcanzados por Bismarck, la ruptura solo podía lograrse mediante una constitucionalización de esta política

45 Esta parece ser la opinión de Sinzheimer, que piensa que el interés de Gurvitch por el concepto de derecho social se relaciona con su "valor positivo", y no con los factores reales que podrían llevar a la efectivización de la idea ("Eine Theorie des sozialen Rechts", op. cit., p.177).

46 Hugo Sinzheimer, "Über soziologische und dogmatische Methode in der Arbeitsrechtswissenschaft" (1922), ahora en Hugo Sinzheimer, Arbeitsrecht und Soziologie, op. cit., t. II, p. 34.

${ }^{47}$ Hugo Sinzheimer, "Die Krisis des Arbeitsrechts", op. cit., p. 139.

48 Lo que contiene una cierta paradoja: después de denunciar el estatismo alemán, es la preeminencia dada al Estado, aunque sea bajo la forma de servicio público, lo que impide que la doctrina francesa conciba al constitucionalismo social en términos de derechos sociales en el marco del IV República.

49 Se observará que cuando Gurvitch intentó reintroducir el problema de los derechos sociales en los debates constituyentes franceses de 1945-46, la referencia a Weimar desapareció, ahora reemplazada por el New Deal de Estados Unidos. Cf. Carlos M. Herrera, "Les droits sociaux, entre démocratie et droits de l'homme", Prefacio de la reedición de G. Gurvitch, La Déclaration des droits sociaux, op. cit., pp. V-XXII. Se podría encontrar rastros de estos debates en G. Burdeau, aunque de forma clandestina, especialmente en su visión de los derechos sociales como derechos del hombre situado, inspirada en ciertas concepciones weimarianas, a las que no hace referencia explicita. 
avanzada en términos de derechos sociales, es decir, poniéndola del lado de los ciudadanos, lo que equivalía a ir más allá de sus límites paternalistas. Y el actor de este cambio solo podría ser el excluido del sistema bismarckiano, las organizaciones de trabajadores socialistas.

Lo que era más específico en el constitucionalismo social alemán, por lo tanto, venía a través del sindicalismo. Antes de ser constitucionalizado en 1919, el modelo se codificó en el llamado "Pacto Legien-Stinnes", negociado entre octubre y noviembre de 1918. El acuerdo entre el jefe de la ADGB, Carl Legien, y el líder de los empleadores alemanes, Hugo Stinnes, sentó las bases de la "comunidad de trabajo", por la cual los sindicatos libres (socialistas) estaban comprometidos con una política de colaboración con el capital, cuyos representantes aceptaban ahora una reglamentación de sus relaciones en base a la representación paritaria. Además, este acuerdo permitía desactivar las visiones más radicales de la idea del consejo obrero en el momento de la Revolución de noviembre ${ }^{50}$. Los comentaristas extranjeros fueron unánimes al observar que el poder sindical habia "aumentado enormemente desde la caída del Imperio" y su influencia se había tornado "decisiva en la vida pública". Por su influjo, la legislación social estaba perdiendo "el carácter estrictamente individualista que tenía bajo el Imperio, los sindicatos han podido imponer el reconocimiento de los derechos colectivos de la clase trabajadora, apoyados en la autoridad de sus organizaciones profesionales ${ }^{51}$.

Más que un modelo, el constitucionalismo social alemán aparece ante los ojos de los juristas franceses como el fruto de una historia política, en el mejor de los casos de un espíritu anti-individualista. Las normas sociales recogidas por la Constitución de 1919 eran, sobre todo, una demanda de los sindicatos socialistas para un programa de socialización. Y como tal, era dificil de entender en Francia, con su percepción de una Alemania siempre atravesada por tendencias antidemocráticas. No es casualidad que Georges Burdeau juzgue el reconocimiento constitucional de los derechos sociales como problemático para un sistema parlamentario, porque el Parlamento querria entonces reclamar competencias de las que solo el Ejecutivo "por su estructura y sus medios de información, sin embargo, estaría en condiciones de llevar a cabo" ${ }^{52}$.

Aun las instituciones obreras, como los consejos de fábricas, fueron vistas como una expresión de una sindicalización obligatoria dirigida a introducirla en la máquina estatal, que era propia del estatismo económico alemán y, por lo tanto, del autoritarismo. No había un Estado social comparable en Francia, donde el seguro social se desarrollará solo a partir de las leyes de 1928 y 1930, y

${ }^{50}$ Para esta concepción, los Betriebsräte no debian reemplazar al Estado: esta es la diferencia primordial con las fuerzas influenciadas por la experiencia bolchevique, quienes vieron en los concejos la forma politica de la dominación del proletariado. Pero para los socialdemócratas mayoritarios, la exclusión de otras clases de la representación política llevaría a la ruina económica y la contrarrevolución.

51 Entre muchos ejemplos, ver Marcel Berthelot, Les lois du travail en Allemagne, Crès, Paris, 1924, p. XVI-XVII ; E. Molitor, "La nouvelle constitution allemande du travail", Mélanges Lambert, LGDJ, Paris, 1938, t. III, p. 270.

52 Georges Burdeau, Le système parlementaire..., op. cit., p. 49. Burdeau va más allá porque critica la idea de una constitución social y económica, que expresaría únicamente los intereses transitorios de un grupo de la colectividad y lleva a debilitar la estructura politica del Estado. 
los teóricos del derecho social desconfiaban de un Estado poderoso, e incluso en el caso de Duguit, de los sindicatos obreros.

Sin embargo, los observadores franceses no se equivocaban respecto a las dificultades del modelo alemán. Para Edmond Vermeil, esa idea de comunidad de trabajo significaba el "abandono sistemático de la lucha de clases». Por ese medio, los socialistas pedian a la burguesía que colaborara con el proletariado. Pero "esta colaboración sólo puede ser, de hecho, una lucha, un conflicto. O el proletariado dominará a la burguesía o es la burguesía quien terminará venciendo al proletariado" ${ }^{53}$.

Las consecuencias afectaron no solo al destino del socialismo, sino también a la fortuna del sistema político democrático. Como ya lo señalaba Georges Scelle en 1921, en su reseña del libro de $\mathrm{R}$. Brunet antes recordado. "Estaría casi tentado de decir que todo el futuro político y constitucional de Alemania depende de cómo se resuelva la cuestión social; según sea en beneficio del sindicalismo socialdemócrata o en beneficio de las organizaciones patronales, tendemos ocasión de ver si la Constitución y las instituciones democráticas se convierten en una realidad, o por el contrario, quedan como textos de fachada y transición ${ }^{54}$. Scelle no se equivocaba en la disyuntiva, pero la respuesta al dilema tendría consecuencias mucho más dramáticas de lo que podía por entonces imaginar.

Enviado el (Submission Date): 27/04/2019

Aceptado el (Acceptance Date): 10/05/2019

\footnotetext{
${ }^{53}$ Edmond Vermeil, La Constitution de Weimar..., op. cit., p. 391, p. 400.

${ }^{54}$ Revue du Droit Public, 1921, p. 578.
} 